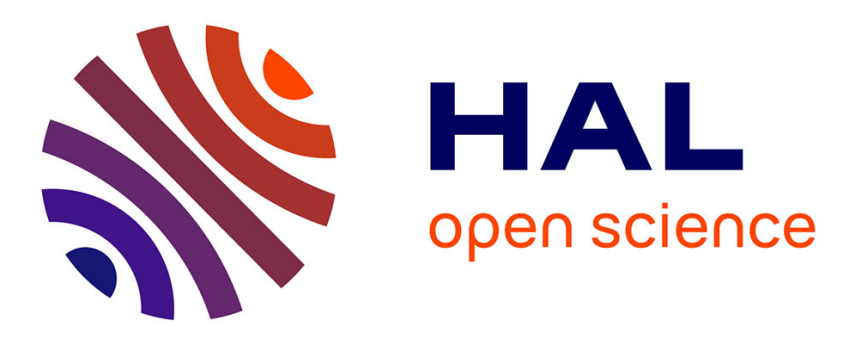

\title{
Adsorption of copper, cadmium, lead and zinc onto a synthetic manganese oxide
}

Loïc Della Puppa, François Bordas, Michael Komárek, Jean-Claude Bollinger, Emmanuel Joussein

\section{- To cite this version:}

Loïc Della Puppa, François Bordas, Michael Komárek, Jean-Claude Bollinger, Emmanuel Joussein. Adsorption of copper, cadmium, lead and zinc onto a synthetic manganese oxide. Journal of Colloid and Interface Science, 2013, 399, pp.99-106. 10.1016/j.jcis.2013.02.029 . hal-00922675

\section{HAL Id: hal-00922675 \\ https://hal-unilim.archives-ouvertes.fr/hal-00922675}

Submitted on 29 Dec 2013

HAL is a multi-disciplinary open access archive for the deposit and dissemination of scientific research documents, whether they are published or not. The documents may come from teaching and research institutions in France or abroad, or from public or private research centers.
L'archive ouverte pluridisciplinaire HAL, est destinée au dépôt et à la diffusion de documents scientifiques de niveau recherche, publiés ou non, émanant des établissements d'enseignement et de recherche français ou étrangers, des laboratoires publics ou privés. 


\section{Adsorption of $\mathrm{Cu}^{2+}, \mathrm{Cd}^{2+}, \mathrm{Pb}^{2+}$ and $\mathrm{Zn}^{2+}$ onto a synthetic Mn oxide}

Loïc Della Puppa ${ }^{\mathrm{a}, \mathrm{b}}$, Michael Komárek ${ }^{\mathrm{a},{ }^{*}}$, François Bordas ${ }^{\mathrm{b}}$, Jean-Claude Bollinger ${ }^{\mathrm{b}}$, Emmanuel Joussein ${ }^{\mathrm{b}}$

${ }^{a}$ Department of Environmental Geosciences, Faculty of Environmental Sciences, Czech University of Life Sciences Prague, Kamýcká 129, Prague 6 - Suchdol, 165 21, Czech Republic

${ }^{b}$ Groupement de Recherche Eau Sol Environnement, Université de Limoges, Faculté des Sciences, 123 Avenue Albert Thomas, 87060 Limoges, France

* Corresponding author:

e-mail: komarek@fzp.czu.cz - Phone: +420 224383857 - Fax: +420 234383778 


\begin{abstract}
Due to its simple and inexpensive synthesis, a new amorphous hydrous manganese oxide (AMO) has been studied as a possible chemical stabilizing agent for soils contaminated with metals. Preliminary experiments evaluating the stability of AMO in pure water have reported only minor dissolution (5.70\% and $0.24 \%$ depending on the w/v ratio). Sorption kinetics have shown fast metal adsorption, especially for $\mathrm{Pb}$. The sorption capacities of AMO for $\mathrm{Cu}, \mathrm{Cd}, \mathrm{Pb}$ and $\mathrm{Zn}$ have been described and compared with synthetic birnessite for $\mathrm{pH} 4$ and 5.5. Both oxides show similar sorption capacities at $\mathrm{pH} 4$ despite the fact that birnessite characteristics ( $\mathrm{pH}$ of zero point charge, specific surface area and cation exchange capacity) are more favorable for metal sorption. Moreover, the $\mathrm{pH}$ adsorption-edges show that the AMO is more $\mathrm{pH}$-dependent than birnessite.
\end{abstract}

\title{
Keywords
}

Manganese oxide, Sorption, Divalent metal cations, Birnessite

\section{Highlights}

- A new amorphous hydrous manganese oxide (AMO) has been studied $>$ Easy and cheap to synthesize Sorption capacities of $\mathrm{Cu}^{2+}, \mathrm{Cd}^{2+}, \mathrm{Pb}^{2+}$ and $\mathrm{Zn}^{2+}$ equal to that of birnessite $\mathrm{A}$ possible chemical stabilizing agent for soils contaminated with metals. 


\section{Introduction}

The behavior and mobility of metals/metalloids in soils are significantly influenced by their sorption onto soil organic matter, clay minerals and secondary Fe and Mn (oxy)hydroxides (hereafter referred to as oxides). The main immobilization processes include adsorption and surface precipitation, and the parameters affecting these processes are mainly soil $\mathrm{pH}$, soil composition and speciation of metals/metalloids [1].

Based on these assumptions, several methods for soil remediation (when contaminated with metals) have been studied, by the use of various amendments, e.g. zerovalent Fe, compost, phosphate, lime, clay minerals and a combined chemical method with phytoremediation [2]. These methods are all based on the reduction of metal/metalloid mobility through adsorption, complexation and (co)precipitation processes [3]. Chemical stabilization using oxides represents another important stabilization practice. The application of zerovalent iron as a precursor of Fe oxides has been successfully studied for metal immobilization [4-6]. Despite their high immobilization potential, Mn oxides have been examined to a much lesser extent for chemical stabilization than Fe oxides $[3,7]$.

Being ubiquitous soil components, Mn oxides could offer a major sink source for metal immobilization [7-9]; they typically occur as coatings and fine-grained aggregates and moreover can efficiently control the evolution and mobility of metals even at low concentrations in soils [10-12]. Except for As and $\mathrm{Cr}$ [3, 13-15], the use of synthetic Mn oxides has not been extensively assessed with regard to metal stabilization in contaminated soils despite such favorable and strong sorption characteristics [7]. Manganese oxides could therefore become a valuable alternative in chemical stabilization $[15,16]$. The aim of the present study is to evaluate the sorption properties of a new synthetic amorphous hydrous 
manganese oxide (AMO) prepared according to a protocol modified from that developed by Ching et al. [17], which is commonly applied for the preparation of birnessite. 


\section{Materials and methods}

The solutions of metal elements introduced into sorption experiments were prepared using hydrated $\mathrm{CuNO}_{3}, \mathrm{CdNO}_{3}, \mathrm{ZnNO}_{3}$ and $\mathrm{PbNO}_{3}$ salts. A $0.01 \mathrm{M} \mathrm{NaNO}_{3}$ solution served as the background electrolyte to set the ionic strength of the experimental solution. Deionized water from the Sci-aqua water system (with a conductivity of less than $0.14 \mu \mathrm{S} / \mathrm{cm}$ ) was part of all solution preparations. All chemicals used were of analytical grade.

\subsection{Synthesis of the manganese oxides}

The amorphous manganese oxide (AMO) was prepared according to a modified solgel procedure [17] (advised for the preparation of birnessite), consisting of adding 0.5 L of a 1.4 $\mathrm{M}$ glucose solution to $0.5 \mathrm{~L}$ of a $0.4 \mathrm{M} \mathrm{KMnO}_{4}$ solution. After gel formation, the solution was filtered and washed with $2 \mathrm{~L}$ of pure water in order to remove the excess of reactants. The gel was subsequently dried at room temperature. The protocol modification omitted the heating step (at $400^{\circ} \mathrm{C}$ ) after gel drying. Pure birnessite was prepared according to the McKenzie [18] protocol, which consists of adding dropwise $1 \mathrm{~L}$ of a $1 \mathrm{M} \mathrm{HCl}$ solution to 1.25 $\mathrm{L}$ of a $0.5 \mathrm{M}$ boiling $\mathrm{KMnO}_{4}$ solution. The solution was then left to cool at room temperature, filtered and washed with pure water.

\subsection{Characterization of the manganese oxides}

X-ray diffraction (XRD) patterns were obtained using a Brucker-AXS D 5005 powder diffractometer featuring $\mathrm{CuK} \alpha$ radiation $(\lambda \mathrm{K} \alpha=0.154186 \mathrm{~nm})$ and a graphite back monochromator. These patterns were derived under the following conditions: a dwell time of $2 \mathrm{~s}$, and a $0.04^{\circ}(2 \theta)$ step. FTIR spectra were generated from a ThermoFischer Scientific 380 infrared spectrometer (Nicolet) by implementing the attenuated total reflection (ATR) method. IR spectra were collected between 500 and $4,000 \mathrm{~cm}^{-1}$, with a resolution of $4 \mathrm{~cm}^{-1}$. The commercially available software OMNIC (Nicolet Instruments) was run for the data 
acquisition and spectral analysis. Oxide morphology was investigated using scanning electron microscopy (SEM, Philips XL 30, 20 kV, SERMIEL - Université de Limoges, France) coupled with an EDS apparatus; over 50 SEM-EDS analyses were performed for each sample studied. The BET surface was determined at $105^{\circ} \mathrm{C}$ with the Quantachrome Instruments Nova ${ }^{\circledR}$ e-Series equipment.

The $\mathrm{pH}$ of the synthesized oxides was measured using either a $1 / 2.5 \mathrm{w} / \mathrm{v}$ ratio with deionized water or a $1 \mathrm{M} \mathrm{KCl}$ (ISO 10390) in conjunction with a Crimson micro pH $2000 \mathrm{pH}-$ meter equipped with a combined electrode (reference $\mathrm{Ag} / \mathrm{AgCl}$ ) calibrated with two buffers ( $\mathrm{pH} 4.01$ and 7.00 at $25^{\circ} \mathrm{C}$ ). The acidity constant and $\mathrm{pH}_{\mathrm{ZPC}}$ (Zero Point Charge) were determined by acid-base titration according to Davranche et al. [19]. The zeta potential was calculated using Alphaphot-2 NIKON with the software ZetaPhoremeter II and a w/v ratio of 1/500. The cation exchange capacity (CEC) was measured by employing the cobalt hexammine trichloride method (NF EN ISO 23470). These samples were mixed for 3 hours with a $0.016 \mathrm{M}$ cobalt hexammine trichloride solution at a w/v ratio of $1 / 5$ and filtered on $0.2-$ $\mu \mathrm{m}$ cellulose nitrate filter (VWR).The excess $\mathrm{Co}\left(\mathrm{NH}_{3}\right)_{6}{ }^{3+}$ was analyzed with a UV-visible spectrophotometer (Shimadzu UV-160) at $470 \mathrm{~nm}$.

The average oxidation state of Mn was determined by applying the method described in Murray et al. [20]. $100 \mathrm{mg}$ of solid was suspended in $50 \mathrm{~mL}$ of water; then, $10 \mathrm{~mL}$ of NaI solution (90 g in $150 \mathrm{~mL}$ ) were added followed by $3 \mathrm{~mL}$ of $2 \mathrm{M} \mathrm{H}_{2} \mathrm{SO}_{4}$. The solution was stirred until achieving complete dissolution of the solid and titrated with a $0.18 \mathrm{M} \mathrm{Na}_{2} \mathrm{~S}_{2} \mathrm{O}_{4}$ solution. Each characterization was performed in triplicate. 


\subsection{AMO stability in pure water}

The stability of this AMO was evaluated in a preliminary experiment that consisted of monitoring both the $\mathrm{pH}$ and amounts of $\mathrm{Mn}$ and $\mathrm{K}$ released into the solution during stirring in pure water at two different w/v ratios (1/500 and 1/10).

Oxygen consumption was measured for 11 days in the Oxytop® (WTW) system in order to observe the influence of AMO on microorganism respiration at a 1/500 w/v ratio and $22^{\circ} \mathrm{C}$

\section{$2.4 \quad$ Kinetics of metal sorption onto AMO and birnessite}

Kinetic batch experiments were performed at two different $\mathrm{pH}$ values (4.0 and 5.5) and at a $1 / 500 \mathrm{w} / \mathrm{v}$ ratio. The $\mathrm{pH}$ was manually set using $0.1 \mathrm{M} \mathrm{HNO}_{3}$ and $0.1 \mathrm{M} \mathrm{NaOH}$ solutions. The initial metal concentration was fixed at $1 \mathrm{mM}$. After stirring (200 rpm on a KS501 digital, IKA Labortechnik), samples were filtered using a $0.2-\mu \mathrm{m}$ cellulose acetate filter (VWR); moreover, the concentrations of studied metal elements $(\mathrm{Cu}, \mathrm{Cd}, \mathrm{Zn}, \mathrm{Pb})$ remaining in solution were analyzed by means of ICP-OES (Agilent Technologies 720 Series). The difference between initial and final values provided the metal element amounts adsorbed per gram of adsorbent. Each experiment was conducted in triplicate (the values shown represent the average and standard deviation).

Two distinct kinetic models were introduced for data interpretation: i) a pseudo-first order, and ii) a pseudo-second order [21]. Modeling results indicated that only the pseudosecond order kinetic model actually fit the data:

$$
\frac{d q_{t}}{d t}=k_{2}\left(q_{e}-q_{t}\right)^{2}
$$


where $\mathrm{k}_{2}$ is the pseudo-second-order rate constant $\left(\mathrm{g} \cdot \mathrm{mmol}^{-1} \cdot \mathrm{min}^{-1}\right), \mathrm{q}_{\mathrm{e}}\left(\mathrm{mmol} \cdot \mathrm{g}^{-1}\right)$ the amount adsorbed at equilibrium, and $\mathrm{q}_{\mathrm{t}}\left(\mathrm{mmol} \cdot \mathrm{g}^{-1}\right)$ the amount adsorbed at time $t$. When $\mathrm{t}=0$ and $\mathrm{q}_{\mathrm{t}}=$ 0 (initial conditions), the equation becomes:

$$
\frac{t}{q_{t}}=\frac{1}{k_{2} q_{e}^{2}}+\frac{t}{q_{e}}
$$

The adsorption rate constant $\mathrm{k}_{2}$ can be obtained from the slope of the linear plot of $t / q_{t}=f(t)$.

\subsection{Sorption isotherms and adsorption edges}

Sorption experiments (with $\mathrm{Cu}, \mathrm{Cd}, \mathrm{Zn}, \mathrm{Pb}$ ) were performed using $24 \mathrm{~h}$ as the equilibrium time (as determined from the kinetic study) at a w/v ratio of 1/500 in HD-PE bottles. For sorption isotherms, these experiments were conducted at two $\mathrm{pH}$ values (4.0 and 5.5). Each metal element was studied both individually and simultaneously in order to evaluate possible competition effects. The $\mathrm{pH}$ was manually set using $0.1 \mathrm{M} \mathrm{HNO}_{3}$ and $0.1 \mathrm{M}$ $\mathrm{NaOH}$ solutions. After stirring (200 rpm), samples were filtered (with a $0.2-\mu \mathrm{m}$ cellulose acetate filter) and the concentrations of $\mathrm{Cu}, \mathrm{Cd}, \mathrm{Zn}, \mathrm{Pb}$ and $\mathrm{Mn}$ remaining in solution were analyzed. The difference between initial and final values yielded the amount of metal elements adsorbed per gram of adsorbent. Each experiment was conducted in triplicate, with the values shown representing the average and standard deviation.

According to $\mathrm{pH}$ and metal concentration values, the potential risks of metal precipitation were predicted by speciation modeling using the MINEQL+4.6 software [22]. Sorption isotherms could therefore be constructed according to two distinct approaches: i) classical isotherms, where the total amount of metals was added at the start of the experiment; and ii) multiple addition sorption isotherms, where a solute concentration of $1 \mathrm{mM}$ was 
initially introduced and another $1 \mathrm{mM}(1 \mathrm{~mL}$ of a $50 \mathrm{mM}$ solution) was subsequently added every day in order to limit precipitation risks at higher metal concentrations. Each step lasted $24 \mathrm{~h}$ (i.e. the equilibrium time as determined from the kinetic study). The data were fitted to the Langmuir isotherm as follows:

$$
S=\frac{S_{\max } * K *\left[M^{2+}\right]}{1+K *\left[M^{2+}\right]}
$$

where $S_{\max }$ denotes the maximum sorption capacities $\left(\mathrm{mmol}^{-1} \mathrm{~g}^{-1}\right), \mathrm{K}$ the Langmuir constant $\left(\mathrm{L} . \mathrm{mmol}^{-1}\right)$, and $\left[\mathrm{M}^{2+}\right]$ the concentration of metal elements in solution (mmol.L $\left.\mathrm{L}^{-1}\right)$. The Langmuir sorption isotherm parameters were obtained from the Bolster and Hornberger spreadsheets [23] using nonlinear fitting models based on the least sum of squared errors.

Adsorption edge studies were conducted with metal concentrations fixed at $1 \mathrm{mM}$, and the $\mathrm{pH}$ was manually set to vary from 4.0 to 7.5 in the presence of $0.1 \mathrm{M} \mathrm{HNO}_{3}$ and $0.1 \mathrm{M}$ $\mathrm{NaOH}$ solutions. The samples were then filtered (using $0.2-\mu \mathrm{m}$ cellulose acetate) and the filtrate was analyzed to determine the remaining metal concentration in solution. Each experiment was conducted in triplicate; the given values represent the average and standard deviation. 


\section{Results and discussion}

\subsection{Characterization of the solids}

SEM images of the amorphous manganese oxide (AMO) are presented in Figure 1 at two different scales. Figure 1a shows that particles are agglomerates several micrometers in size and display conchoidal fractures. The presence of a film covering the surface is characteristic of a solid originating from a sol-gel procedure (Fig. 1b) and does not reflect any defined morphology that would indicate the amorphous nature of the solid. When using chloroethylene instead of glucose, the Mn oxide exhibits a cluster of small needle-shaped crystals [24], thus underscoring the impact of the organic compound type. The measured particle size distribution follows a Gaussian curve $(600-1,200 \mathrm{~nm})$, with a maximum at 1,000 nm.

Figure 2a shows the XRD spectra of both the AMO and birnessite. Despite a welldefined yet low-intensity peak, i.e. matching the pattern of birnessite, the XRD spectra reveal that the synthesized Mn oxide is amorphous. When chloroethylene is selected as the organic compound for manganese oxide synthesis, the characteristic peaks of crystallized manganese oxide are present [24]. This result highlights the critical role of the organic compound used for the synthesis. The prepared birnessite is a single-phase mineral, as indicated by three peaks at 3.68, 2.43 and $1.42 \AA$ in its XRD pattern (XRD JCPDS file 23-1239), which prove to be characteristic for this mineral phase $[17,25]$.

The AMO IR spectra (Fig. 2b) displays bands at around 1,100 $\mathrm{cm}^{-1}, 2,900$ and 3,000$3,600 \mathrm{~cm}^{-1}$, which might possibly correspond to glucose bands ( $v \mathrm{C}-\mathrm{O}, \mathrm{vC}-\mathrm{Hn}$ and $\left.-\mathrm{O}-\mathrm{H}\right)$ originating from the glucose residue present even after washing (correlated with the organic carbon content, $17.0 \mathrm{mg}$ of $\mathrm{C} / \mathrm{g}$ ). The band around 3,000-3,600 $\mathrm{cm}^{-1}$ might also correspond to the stretching vibrations of both the $\mathrm{O}-\mathrm{H}$ group of water molecules and the lattice $\mathrm{O}-\mathrm{H}$ groups 
[26]. The band between 400 and $800 \mathrm{~cm}^{-1}$ can be attributed to the Mn-O lattice vibrations, while position and/or intensity changes can be associated with changes in the octahedral layered substructure [27-29]. The band around $1,600 \mathrm{~cm}^{-1}$ is typically attributed to $\mathrm{O}-\mathrm{H}$ bending vibrations combined with $\mathrm{Mn}$ atoms [25]. When heating the $\mathrm{AMO}$ to $140^{\circ} \mathrm{C}$, a peak appears around $600 \mathrm{~cm}^{-1}$, corresponding to the birnessite structure [28-30]. After heating, the AMO structure changes and shows a better fit with the birnessite spectra, meaning that AMO becomes unstable as temperature increases. At $140^{\circ} \mathrm{C}$, the band around $1,000 \mathrm{~cm}^{-1}$ disappears, which could be due to glucose degradation. The AMO can be considered as a protophase of birnessite during the sol-gel synthesis.

\subsection{Chemical properties of the solids}

Table 1 summarizes the main physicochemical characteristics of the AMO and birnessite. The difference between $\mathrm{pH}_{\mathrm{H} 2 \mathrm{O}}$ and $\mathrm{pH}_{\mathrm{KCl}}$ values of birnessite indicates the presence of $\mathrm{H}^{+}$sorbed on the surface, which is not the case for AMO. Surface acidity constants $\mathrm{pKa}_{1}$ and $\mathrm{pKa}_{2}$ are acidic for birnessite, while those of the AMO are basic. At $\mathrm{pH}$ 4.0 and 5.5 (i.e. the conditions of the sorption experiments), the birnessite surface is therefore theoretically negatively charged, as opposed to the AMO surface, which is theoretically positively charged. The $\mathrm{pH}_{\mathrm{ZPC}}$ value of the AMO is basic (8.3), in contrast with other $\mathrm{Mn}$ oxides prepared from the oxidation, for example, of trichloroethylene (pH 3.7) [24]. This value has been confirmed by a fast method that consists of measuring the $\mathrm{pH}$ value of oxide suspension (1/100 w/v ratio) in a $0.01 \mathrm{M} \mathrm{NaNO}_{3}$ solution, which lies near the $\mathrm{pH}_{\mathrm{ZPC}}$ value [31]. For AMO, the measured $\mathrm{pH}$ under this condition equals 8.20 (3.14 for birnessite). This value is similar to that obtained by following the Davranche et al. protocol [19]. The results derived with birnessite synthesized using concentrated $\mathrm{HCl}$ and hot $\mathrm{KMnO}_{4}$ solutions are in good agreement with values found in the literature [32]; however, this value is protocoldependent [33]. The $\mathrm{pH}_{\mathrm{ZPC}}$ values found here suggest more favorable adsorption for cations 
onto birnessite than onto AMO, due to the negative surface charge on birnessite at $\mathrm{pH} 4$ and 5.5 .

The CEC value of birnessite ( $247 \mathrm{meq} / 100 \mathrm{~g})$ is greater than that of the AMO (34 meq/100 g) and in good agreement with the value observed by Golden et al. [34]. Moreover, the specific surface area of birnessite is greater than that of the AMO (Table 1); however, the various BET values listed in the literature $\left(32.6 \mathrm{~m}^{2} / \mathrm{g}\right.$ [35], $34.2 \mathrm{~m}^{2} / \mathrm{g}$ [26], $19.3 \mathrm{~m}^{2} / \mathrm{g}$ [36]) can be explained by the fact that BET analyses are strongly temperature-dependent. Using trichloroethylene instead of glucose, Li and Schwartz [24] found a specific surface area of $23.6 \mathrm{~m}^{2} / \mathrm{g}$, which is closer to the AMO value (14.8).

All of the measured parameters seemed to be predicting better sorption properties for birnessite: higher CEC and BET, and a theoretically negatively charged surface due to its $\mathrm{pH}_{\mathrm{ZPC}}$ value and the $\mathrm{pH}$ value set during the adsorption experiments. The average $\mathrm{Mn}$ oxidation state (AOS) in the AMO is about 2.52, which indicates that one Mn atom can be linked to $1.26 \mathrm{O}$ atoms. Moreover, after $24 \mathrm{~h}$ of stirring in pure water at a w/v ratio of $1 / 500$, this AOS value rises from 2.52 to 3.04, thus reflecting an increasing average Mn oxidation state. This outcome could be due to the release of weakly bound Mn from the AMO surface with an AOS greater than 3.04, originating from a residual fraction of the $\mathrm{KMnO}_{4}$ reactant.

\subsection{Stability of the AMO in pure water}

The w/v ratio of 1/500 reveals, to some extent, the AMO behavior just before natural dispersion into the soil (migration, transport by pore water), whereas the $1 / 10$ ratio simulates the behavior before dispersion, when the solid is locally located. For both ratios, the $\mathrm{pH}$ is close to 7 and remains stable over time (Fig. 3). The AMO appears to be stable for both the $1 / 500$ and $1 / 10 \mathrm{w} / \mathrm{v}$ ratios after $200 \mathrm{~h}$ of stirring in pure water. Two dissolution steps (Fig. 3a) are observable for the 1/500 w/v ratio; the first step is reached after $20 \mathrm{~h}$ of stirring and might 
correspond to the release of weakly adsorbed $\mathrm{Mn}$. The second step is reached after $200 \mathrm{~h}$ and might correspond to dissolution of the AMO (with Mn released into the solution accounting for $5.7 \%$ of total AMO content). For the 1/10 ratio, the AMO seems to be more stable, with less dissolution due to displacement of the dissolution balance within the solution. Another Mn dissolution step is observable (Fig. 3b) near $10 \mathrm{~h}$, probably due to dissolution and/or release of the weakly bound Mn (an amount representing $0.24 \%$ of the solid). Regardless of the w/v ratio, the AMO seems to be stable in water. The potassium in solution was stable throughout the experiment and might have originated from the weakly bound fraction at the oxide surface and/or, to some extent, AMO dissolution. The fact that Ching et al. [17] found no potassium inside the birnessite structure synthesized by the sol-gel method however means that the potassium most likely originated from both the weakly bound fraction at the oxide surface and the residue of $\mathrm{KMnO}_{4}$ used during the AMO synthesis.

The effect of the presence of AMO and birnessite on microbial respiration was monitored through $\mathrm{O}_{2}$ consumption measurements. In the presence of birnessite, low $\mathrm{O}_{2}$ consumption was observed (S. 1). On the other hand, the AMO increased the level of $\mathrm{O}_{2}$ consumption, especially after $25 \mathrm{~h}$, which corresponds to the activation of natural microbial flora. This result demonstrates that the AMO may exert no significant toxic effect on microbial flora. The time necessary to activate microbial flora corresponds to the start of the $2^{\text {nd }}$ step observed during Mn solubilization, a determination that could be explained by the fact that the degradation of residual glucose (used in AMO synthesis) enhances microbial activity, thus improving either AMO dissolution or the release of Mn weakly bound to the solid. The organic carbon content in AMO lies near $17.0 \mathrm{mg}$ of $\mathrm{C} / \mathrm{g}$, which confirms the presence of an organic glucose residue. 


\section{$3.4 \quad$ Sorption kinetics}

The adsorption of metals on both solids occurs during the first few minutes (S. 2), with $\mathrm{Pb}$ being the most quickly adsorbed. During subsequent experiments, a time of $24 \mathrm{~h}$ was set as the optimal contact time on the basis of these results and for practical reasons. In the case of birnessite, the sorption of metal elements is not modified by the $\mathrm{pH}$ value over the studied range, which can be explained by: the high cationic exchange capacity, high specific surface area, and low $\mathrm{pH}_{\mathrm{ZPC}}$ value (2.7) of birnessite. Sorption on the AMO is more acutely affected by $\mathrm{pH}$ value (i.e. better at $\mathrm{pH} 5.5$ than at $\mathrm{pH} 4.0$ ) due to its lower CEC, specific surface area and $\mathrm{pH}_{\mathrm{ZPC}}$ (8.3). The adsorption of metal elements increases the $\mathrm{pH}_{\mathrm{ZPC}}$ values (data not shown herein), thus indicating that specific adsorption occurs on both oxides [4]. Manganese oxides do in fact adsorb metals primarily in the form of specific adsorption [37, 38].

Pseudo-first and pseudo-second order kinetic models have been applied to the experimental data, whose fit shows that the pseudo-second order is more suitable. The parameters calculated using linear regression are listed in Table 2. The pseudo-second order rate constant $\left(\mathrm{k}_{2}\right)$ represents the affinity of the metal element for the solid. When comparing the affinity of these metal elements for AMO and birnessite, it appears that they present a greater affinity for birnessite regardless of $\mathrm{pH}$ (especially in the case of $\mathrm{Pb}$ ). This greater affinity of metal elements for birnessite can be partially explained by the $\mathrm{pH}_{\mathrm{ZPC}}$ and BET values, hence resulting in a higher specific surface area and a negatively charged surface under the given experimental conditions, which favor adsorption.

\subsection{Adsorption isotherms}

\subsubsection{Standard isotherms}

As expected, Figure 4 and Table 3 show that the sorption capacities of $\mathrm{Cu}, \mathrm{Cd}, \mathrm{Zn}$ and $\mathrm{Pb}$ increase with $\mathrm{pH}$. For the metal elements studied herein, the sorption capacity $\left(\mathrm{S}_{\max }\right)$ of 
AMO at $\mathrm{pH} 4.0$ respects the following order: $\mathrm{Pb}>\mathrm{Cu}>\mathrm{Zn}>\mathrm{Cd}$, and at $\mathrm{pH} 5.5: \mathrm{Pb}>\mathrm{Cu}>$ $\mathrm{Cd}>\mathrm{Zn}$. For birnessite, at $\mathrm{pH} 4: \mathrm{Pb}>\mathrm{Cu}>\mathrm{Zn}>\mathrm{Cd}$, and at $\mathrm{pH} 5.5: \mathrm{Pb}>\mathrm{Cu} \approx \mathrm{Cd}>\mathrm{Zn}$. Similar results have been observed by other authors [39, 40]. Lead is strongly adsorbed on both oxides. It has been shown that $\mathrm{Pb}$ is capable of occupying both the interlayer and surface edge sites $[10,40]$. When the metal elements are considered individually, birnessite is more effective in sorbing metal elements than the AMO, as justified by the respective $\mathrm{K}$ values (Table 3). Regarding maximum sorption capacities $\left(\mathrm{S}_{\max }\right)$, the values are similar for the two sorbents despite the fact that birnessite has a greater CEC and specific surface area while a lower $\mathrm{pH}_{\mathrm{ZPC}}$. The accessibility of surface sites relative to both solids most certainly differs.

The results presented in Figure 5 were obtained by mixing multi-metal element solutions, containing all four elements, with the solids in order to highlight potential competition phenomena. Compared to the results found for each metal examined individually (Fig. 4), the amount of adsorbed $\mathrm{Cd}$ and $\mathrm{Zn}$ decreases as the amounts of $\mathrm{Cu}$ and $\mathrm{Pb}$ increase. Lead is the most strongly sorbed and the main competitor, displaying high affinity for both oxides. These results are in good agreement with the kinetic results (Table 2), as a consequence of the competition taking place between metal elements during their sorption; as previously shown, $\mathrm{Cd}$ and $\mathrm{Zn}$ have less affinity for the oxides than $\mathrm{Cu}$ and $\mathrm{Pb}$.

Figure 6 shows the total amount of metals sorbed onto the solid vs. the total amount of metal in solution at equilibrium during the competition experiments (Fig. 5). It appears that despite the higher CEC and specific surface area of birnessite, the total sorbed amount is similar for both solids, except at $\mathrm{pH}$ 4.0. Therefore, the effective sorption of metal elements by AMO and birnessite is not directly correlated with their physicochemical properties (CEC, specific surface area, $\left.\mathrm{pH}_{\mathrm{ZPC}}\right)$. To explain these results, the surface charge of AMO was determined by zetametry (Fig. 7). With a freshly prepared AMO suspension, a $\mathrm{pH}_{\mathrm{ZPC}}$ value of 
9.0 was obtained, i.e. close to the value found by titration. Under these conditions, the variation in surface charge vs. $\mathrm{pH}$ is small and not correlated with either the protonation or deprotonation of the surface. However, when the AMO is in suspension for several days before the determination step, the $\mathrm{pH}_{\mathrm{ZPC}}$ value output by zetametry equals 4.8 . Under such conditions, the charge increases as $\mathrm{pH}$ values decrease, which is in good agreement with the protonation. These results have shown that AMO surface properties change with the contact time in aqueous solutions. This instability may be explained by the release of manganese weakly bound to the solid or by hydration of the newly-formed oxide or residual $\mathrm{MnO}_{4}{ }^{-}$ions, which are unstable in solution. Under the experimental conditions of sorption isotherms $(\mathrm{pH} 4$ or 5.5), the surface charge of AMO is thus near zero or even negative, which could potentially explain the sorption properties of the AMO (Fig. 7).

Moreover, as revealed for example by Tunius and Sköld [41] with Al oxide, the entire specific surface of a solid is not necessarily available for sorption. The Mn sorbed on the oxide surface might also interfere with the specific surface area measurement, thereby clogging some of the smaller pores and reducing the available area for $\mathrm{N}_{2}$ sorption during the BET measurement [26].

\subsubsection{Multi-adding isotherms}

The speciation of metal elements in the bulk solutions was determined using the speciation program MINEQL+4.6 [22]. The standard databases included with the software were applied. Each metal element has been considered separately, by taking into account the $\mathrm{pH}$ value, temperature, atmospheric $\mathrm{CO}_{2}$, ionic strength, and $\mathrm{Na}$ and $\mathrm{NO}_{3}$ concentrations (from the salt of metal elements as well as the background electrolyte).

The figure $\mathrm{S} .3 \mathrm{a}$ and $\mathrm{b}$ present the speciation of $\mathrm{Cu}$ and $\mathrm{Pb}$ at $\mathrm{pH}$ 5.5. Results for $\mathrm{pH}$ 4.0 were not shown due to the fact that free $\mathrm{Cu}^{2+}$ and $\mathrm{Pb}^{2+}$ account for over $95 \%$ of the total 
metal. Precipitation can occur whenever the concentration exceeds $1 \mathrm{mM}$ for $\mathrm{Cu}$ and $3 \mathrm{mM}$ for $\mathrm{Pb}$. The thermodynamic calculations performed with MINEQL+4.6 indicate that $\mathrm{Cu}$ and $\mathrm{Pb}$ can precipitate at $\mathrm{pH} 5.5$ (as $\mathrm{CuO}$ and $\mathrm{Pb}(\mathrm{OH})_{2}$, respectively). In order to prevent any risk of precipitation, multi-adding batch experiments were conducted: $1 \mathrm{mM}$ of metal elements was added on a daily basis until the desired cumulative amount was reached.

The results obtained for $\mathrm{Pb}$ and $\mathrm{Cu}$ at $\mathrm{pH} 5.5$ by means of simple (classical) and multiadding isotherms are similar $(\mathrm{S} .3 \mathrm{c}, \mathrm{d})$, which confirms that $\mathrm{Cu}$ and $\mathrm{Pb}$ do not precipitate in the solution under our experimental conditions, despite speciation calculations predicting the formation of $\mathrm{CuO}$ and $\mathrm{Pb}(\mathrm{OH})_{2}$. As previously shown, the AMO and birnessite adsorbed the metal elements very quickly and, consequently, limited the precipitation risk. The random nature of the first step of the precipitation phenomenon should also be mentioned and typically appears as a result of highly oversaturated solutions.

\section{6 pH adsorption edges}

The $\mathrm{pH}$ adsorption edges (Fig. 8) were determined from $\mathrm{pH} 4$ to 8, since below $\mathrm{pH} 4$ the $\mathrm{AMO}$ is altered while above $\mathrm{pH} 8$ metal precipitation occurs. For birnessite, no significant pH effect on metal adsorption has been observed. The sorption rate normally decreases at lower $\mathrm{pH}$ values (as both the surface charge and competition between protons and metal elements increase), though the affinity of birnessite for metals is still sufficient to maintain the high adsorption rate, with sorption starting below $\mathrm{pH} 4$ due to the $\mathrm{pH}_{\mathrm{ZPC}}$ value. For the AMO, the strong sorption of $\mathrm{Pb}$ overshadows the $\mathrm{pH}$ effect; only a small increase in adsorption with increasing $\mathrm{pH}$ values is observable. For $\mathrm{Cu}, \mathrm{Cd}$ and $\mathrm{Zn}$, this adsorbed amount increases significantly as $\mathrm{pH}$ values rise. In comparison with birnessite, the sorption properties of the AMO are considerably affected by $\mathrm{pH}$ values due to the lower affinity of metal elements for AMO. 


\section{Conclusion}

The AMO described in this work seems to be stable in pure water despite the appearance of some dissolution shortly after its contact with water $(5.70 \%$ and $0.24 \%$ of the total amount at 1/500 and 1/10 w/v ratios, respectively). Birnessite and AMO display quite similar sorption capacities for the studied divalent metal cations $(\mathrm{Cu}, \mathrm{Cd}, \mathrm{Pb}, \mathrm{Zn})$; however, birnessite adsorbs faster than the AMO. Even though the CEC of AMO (34 meq/100 g) seems to predict a lower sorption capacity than for birnessite $(247 \mathrm{meq} / 100 \mathrm{~g})$, results indicate that the $\mathrm{AMO}$ acts as an efficient sorbent, especially for $\mathrm{Cu}$ and $\mathrm{Pb}(1.38$ and $2.37 \mathrm{mmol} / \mathrm{g}$ for $\mathrm{AMO}$, and 1.78 and $2.13 \mathrm{mmol} / \mathrm{g}$ for birnessite at $\mathrm{pH}$ 5.5). These findings may be due to the fact that not all of the specific surface is available for sorption as well as to the evolution in surface properties of the AMO in solution vs. time, as determined through the zetametry experiment. Adsorption edges show that the AMO is very sensitive to $\mathrm{pH}$ variations, in addition to being easy and inexpensive to synthesize and capable of providing a valuable amendment for use in stabilizing metals and metalloids in soils. Nevertheless, its stability in various soil types still needs to be evaluated further.

\section{Acknowledgments}

The authors would like to thank both the Czech Science Foundation (project: GAČR P503/11/0840) and the Regional Council for their combined financial support. 


\section{References}

[1] H.B. Bradl, J. Colloid Interface Sci. 277 (2004) 1.

[2] M. Mench, N. Lepp, V. Bert, J.-P. Schwitzguébel, S.W. Gawronsku, P. Schröder, J. Vangronsveld, J. Soils Sediments 10 (2010) 1039.

[3] J.Kumpiene, A. Lagerkvist, C. Maurice, Waste Manage. 28 (2008) 215.

[4] W. Stumm, J.J. Morgan, Aquatic Chemistry, John Wiley and Sons, New-York, 1996.

[5] Y. Roh, S.Y. Lee, M.P. Elless, Environ. Geol. 40 (2000) 184.

[6] C. Bes, M. Mench, Environ. Pollut. 156 (2008) 1128.

[7] M. Komárek, A. Vaněk, V. Ettler, Environ. Pollut. 172 (2013) 9.

[8] J.E. Post, Proc. Natl. Acad. Sci. U. S. A. 86 (1999) 3447.

[9] M.L. Crimi, R.L. Siegrist, Water Res. 38 (2004) 887.

[10] S.E. O’Reilly, M.F. Hochella, Geochim. Cosmochim. Acta 67 (2003) 4471.

[11] S.B. Kanungo, S.S. Tripathy, S.K. Mishra, .B Sahoo, Rajeev, J. Colloid Interface Sci. 269 (2004) 11.

[12] Q. Su, B. Pan, S. Wan, W. Zhang, J. Colloid Interface Sci. 349 (2010) 607.

[13] M. Pantsar-Kallio, S.-P. Reinikainen, M. Oksanen, Anal. Chim. Acta 439 (2001) 9.

[14] A.L. Foster, G.E. Brown, G.A. Parks, Geochim. Cosmochim. Acta 34 (2003) 1937.

[15] M. Mench, J. Vangronsveld, V. Didier, H. Clijsters, Environ. Pollut. 86 (1994) 279. 
[16] G.M. Hettiarachchi, G.M. Pierzynski, M.D. Ransom, Environ. Sci. Technol. 34 (2000) 4614.

[17] S. Ching, D.J. Petrovay, M.L. Jorgensen, S.L. Suib, Inorg. Chem. 36 (1997) 883.

[18] R.M. McKenzie, Mineral. Mag. 38 (1971) 493.

[19] M. Davranche, S. Lacour, F. Bordas, J.-C Bollinger, J. Chem. Educ. 80 (2003) 76.

[20] J.W. Murray, L.S. Balistrieri, B. Paul, Geochim. Cosmochim. Acta 48 (1984) 1237.

[21] G. Limousin, J.-P. Gaudet, L. Charlet, S. Szenknect, V. Barthès, M. Krimissa, Appl. Geochem. 22 (2007) 249.

[22] W.D. Schecher, D.C. McAvoy, MINEQL+: A chemical equilibrium modeling system, version 4.6 for Windows, user's manual, v2.00, Environmental Research Software: Hallowell, Maine, 2003.

[23] C.H. Bolster, G.M. Hornberger, Soil Sci. Soc. Am. J. 71 (2007) 1796.

[24] D.X. Li, F.W. Schwartz, J. Contam. Hydrol. 68 (2004) 39.

[25] P. Di Leo, M.D.R Pizzigallo, V. Ancona, F. Di Benedetto, E. Mesto, E. Schingaro, G. Ventruti, J. Hazard. Mater. 201-202 (2012) 418.

[26] E. Eren, H. Gumus, A. Sarihan, Desalination 279 (2011) 75.

[27] L. Kang, M. Zhang, Z.-H. Liu, K. Ooi, Spectrochim. Acta 67 (2007) 864.

[28] H. Cui, G. Qiu, X. Feng, W. Tan, F. Liu, Clays Clay Miner. 57 (2009) 715.

[29] F. Li, J. Wu, Q. Qin, Z. Li, X. Huang, J. Alloys Compd. 492 (2010) 339. 
[30] Q. Feng, K. Yanagisawa, N. Yamasaki., J. Mater. Sci. Lett. 16 (1997) 110.

[31] E. Cristiano, Y.-J. Hu, M. Siegfried, D. Kaplan, H. Nitsche, Clays Clay Miner. 59 (2011) 107.

[32] J.W. Murray, J. Colloid Interface Sci. 46 (1973) 357.

[33] W.F. Tan, S.J. Lu, F. Liu, X.H. Feng, J.Z. He, L.K. Koopal, Soil Sci. 173 (2008) 277.

[34] D.C. Golden, J.B. Dixon, C.C. Chen, Clays Clay Miner. 34 (1986) 511.

[35] Y. Arai, Appl. Clay Sci. 53 (2011) 572.

[36] H. Yin, X. Feng, M. Liu, W. Tan, G. Qiu, J. Hazard. Mater. 196 (2011) 318.

[37] R.M. McKenzie, Aust. J. Soil Res. 19 (1980) 41.

[38] G. Pan, Y. Qin, X. Li, T. Hu, Z. Wu, Y. Xie, J. Colloid Interface Sci. 271 (2004) 28.

[39] E.F. Covelo, F.A. Vega, M.L. Andrade, J. Hazard. Mater. 140 (2007) 308.

[40] Y. Wang, X. Feng, M. Villalobos, W. Tan, F. Liu, Chem. Geol. 292-293 (2011) 25.

[41] M. Tunius, R. Sköld, Colloids Surf. 46 (1990) 297. 


\section{Figures and Tables captions}

Fig. 1: SEM images of the AMO

Fig. 2: a) XRD spectra (A) of the AMO and birnessite and IR spectra (B) of AMO, b) AMO heated at $140^{\circ} \mathrm{C}$ for $10 \mathrm{~min}, \mathrm{c}$ ) heated for $12 \mathrm{~h}$, and d) and birnessite

Fig. 3: Stability of AMO at a) 1/500 and b) w/v ratio in pure water

Fig. 4: Sorption isotherms of $\mathrm{Cu}, \mathrm{Cd}, \mathrm{Zn}$ and $\mathrm{Pb}$ onto $\mathrm{AMO}$ at a) $\mathrm{pH} 4$ and b) $\mathrm{pH} 5.5$, and birnessite at c) $\mathrm{pH} 4$ and d) $\mathrm{pH} 5.5$ using a 1/500 w/v ratio

Fig. 5: Simultaneous adsorption of $\mathrm{Cu}, \mathrm{Cd}, \mathrm{Zn}$ and $\mathrm{Pb}$ on $\mathrm{AMO}$ at a) $\mathrm{pH} 4$ and b) $\mathrm{pH} 5.5$, and birnessite at c) $\mathrm{pH} 4$ and d) $\mathrm{pH} 5.5$

Fig. 6: Total amount of $\mathrm{Cu}, \mathrm{Cd}, \mathrm{Zn}$ and $\mathrm{Pb}$ adsorbed onto $\mathrm{AMO}$ and birnessite as a function of total concentration in solution at $\mathrm{pH} 4$ and 5.5

Fig. 7: Zeta potential of the AMO in pure water at two different contact times ( 0 days and 15 days) for a range of $\mathrm{pH}$ values

Fig. 8: $\mathrm{pH}$ adsorption edges of $\mathrm{Cu}, \mathrm{Cd}, \mathrm{Zn}$ and $\mathrm{Pb}$ onto a) $\mathrm{AMO}$ and b) birnessite

S. 1: Consumption of $\mathrm{O}_{2}$ in the presence of $A M O$ and birnessite in pure water at a $1 / 500 \mathrm{w} / \mathrm{v}$ ratio

S. 2: Kinetic sorption of $\mathrm{Cu}, \mathrm{Cd}, \mathrm{Zn}$ and $\mathrm{Pb}$ onto $\mathrm{AMO}$ at a) $\mathrm{pH} 4$ and b) $\mathrm{pH} 5.5$, and birnessite at c) and d) using a 1/500 w/v ratio and $1 \mathrm{mM}$ metal element solutions in $0.01 \mathrm{M}$ $\mathrm{NaNO}_{3}$

S. 3: a) $\mathrm{Cu}$ and b) $\mathrm{Pb}$ speciation at $\mathrm{pH} 5.5$ in a $0.01 \mathrm{M} \mathrm{NaNO}_{3}$ solution, and adsorption isotherms of c) $\mathrm{Cu}$ and d) $\mathrm{Pb}$ at $\mathrm{pH} 5.5$ onto AMO: comparison between simple and multiadding isotherms

\section{Table 1:}

Characteristics of both birnessite and AMO

Table 2:

Pseudo-second order kinetic parameters of metal element adsorption onto AMO and birnessite at $\mathrm{pH} 4$ and 5.5

\section{Table 3:}

Characteristics of the modeled Langmuir isotherm for both birnessite and the AMO 
Graphical abstract : SEM image of the AMO 